\title{
DETERMINATION OF DIELECTRIC PERMEABILITY OF SUBSTANCES BY ELECTROMAGNETIC WAVEGUIDE METHOD
}

\author{
Vikt.V. Ovsyanikov ${ }^{1}$, E.R. Beznosova ${ }^{1}$, L.Z. Tsypko ${ }^{1}$, \\ L.A. Filins'kyy ${ }^{1 *}$, Vl.V. Ovsyanikov ${ }^{2}$ \\ ${ }^{1}$ Oles Honchar Dnipro National University, Dnipro, Ukraine \\ ${ }^{2}$ Dnipro University of Technology, Dnipro, Ukraine \\ *e-mail:leonidfil2016@gmail.com
}

\begin{abstract}
A method for determining the complex permittivity of substances by the electromagnetic (EM) waveguide method in the microwave range using electrodynamics and the theory of multilayer dielectric structures is considered. The expression for the complex reflection coefficient of an EM wave in a waveguide with a substance sample is studied. Calculations of the dielectric constant of substances are carried out by analytical and numerical methods using computers. To obtain the desired complex permittivity of a substance, we use the relationship between the expression for the reflection coefficient modulus and the value of the standing wave coefficient over voltage measured in advance in the frequency range. The method is suitable for automation and application in enterprises producing and using fuels, construction and agricultural products. From the found value of the dielectric constant, the quality of substances can be determined. For example, the results of determining the dielectric constant several coals and solid-state foam are given.
\end{abstract}

Keywords: dielectric constant of a substance, electromagnetic waveguide method, VSWR, specific heat of combustion, coal, solid state foam, liquid foam.

Received 20.06.2020; received in revised form 21.08.2020; Accepted 05.09.2020

\section{Introduction}

The non-destructive determination and quality control of various substances with dielectric properties in all areas of the national economy (metallurgical, engineering, oil refining, construction, agricultural etc.) is very relevant. Methods for controlling the quality of substances, for example, infrared, neutron, thermal, radiation, electrical and others [1-7] are well known.

In the development of the basic principles of microwave environment friendly diagnosis of various substances, a great contribution was made by domestic scientists L.M. Brekhovskikh, A.A. Brandt, V.A. Viktorov, B.V. Lunkin, A.S. Sovlukov and foreign M. Born, F. Wolf, Sh.B. Nagy (Hungary), A.F. Harvey (USA) and others.

As an example, Table 1 shows the complex dielectric constant (CDC) values for several important substances with dielectric properties according to the literature and our measurements.

In this paper, with taking into account these works, the search for the relative CDC of substances by analytical and numerical methods using a computer is performed.

\section{Formulation of the problem}

In $[3,4]$ and others, using the equations of electrodynamics and the theory of multilayer dielectric structures, expressions are obtained for the complex reflection and attenuation coefficients of an electromagnetic (EM) wave when it falls on a layer of a substance of thickness $d$ (Fig. 1), commensurate with the EM wavelength.

One of the layers 2 of the structure (Fig. 1) can be a test substance with a thickness commensurate with the length of the working EM wave incident on the interface between, for example, air 1 and test substance 2, as well as substance 2 - air 3 .

Let us consider the expressions for the complex reflection coefficients $R$ from the interfaces of layers $1-2$ and $2-3$ for an EM wave of type TE. 
The complex dielectric constants values for several substances

\begin{tabular}{|c|c|c|c|c|c|}
\hline \multirow[t]{2}{*}{ Substance } & \multicolumn{3}{|c|}{ The complex dielectric constants } & \multirow[t]{2}{*}{$f, \mathrm{GHz}$} & \multirow{2}{*}{ Notes } \\
\hline & $\varepsilon^{\prime}$ & $\varepsilon^{\prime \prime}$ & $\operatorname{tg} \delta$ & & \\
\hline \multirow{4}{*}{ Distilled water } & 79.3 & 7.9 & 0.1 & \multirow{2}{*}{1.74} & Data from $[1,2,5]$ \\
\hline & 75.8 & 10.3 & 0.14 & & Measurements $[1,2,6]$ \\
\hline & 76.3 & 15.6 & 0.20 & \multirow{2}{*}{3.65} & Data from $[1,2,5]$ \\
\hline & 74.3 & 13.2 & 0.18 & & Measurements $[1,2,6]$ \\
\hline Ftoroplast-4 & $1.9-2.2$ & - & $(2-3) \times 10^{-4}$ & 3.0 & Data from $[1,2,5]$ \\
\hline \multirow{2}{*}{ Skinny coal } & $4.1-5.0$ & - & - & \multirow{2}{*}{1.0} & Data from $[1,2,5]$ \\
\hline & 4.5 & - & 0.035 & & Measurements $[1,2,6]$ \\
\hline \multirow{2}{*}{ Coal anthracite } & $>5.0$ & - & - & \multirow{2}{*}{1.0} & Data from $[1,2,5]$ \\
\hline & 5.5 & 1.4 & 0.25 & & Measurements $[1,2,6]$ \\
\hline Solid-state foam & $\begin{array}{c}1.26- \\
1.52\end{array}$ & - & $\begin{array}{c}0.10- \\
1.01\end{array}$ & $2-8.6$ & Measurements $[9,10]$ \\
\hline
\end{tabular}

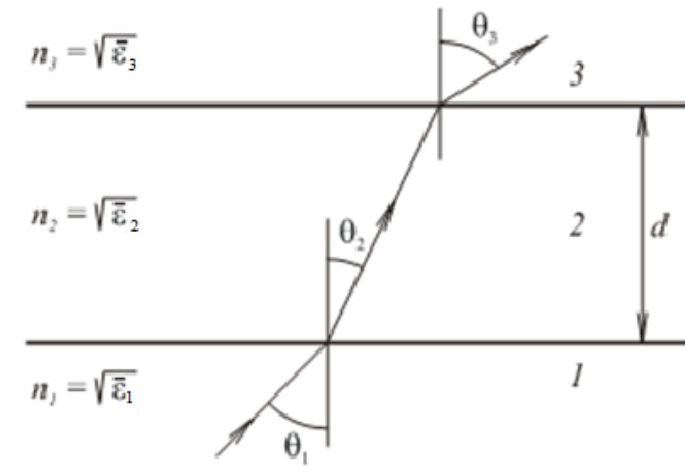

Fig. 1. Three-layer dielectric structure: air -1 , test substance -2 , air -3 .

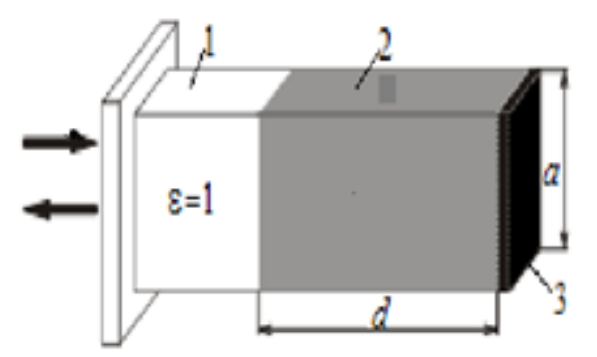

Fig. 2. Schematic representation of WMC: 1 - air; 2 - fuel sample; 3 - metal short circuit.

In this case, media 1-3 are in free space and their dimensions in the horizontal plane tend to infinity. These expressions have the form:

$$
\begin{gathered}
R_{12}=\frac{n_{1} \cos \theta_{1}-n_{2} \cos \theta_{2}}{n_{1} \cos \theta_{1}+n_{2} \cos \theta_{2}}, \\
R_{23}=\frac{n_{2} \cos \theta_{2}-n_{3} \cos \theta_{3}}{n_{2} \cos \theta_{2}+n_{3} \cos \theta_{3}}
\end{gathered}
$$


where

$$
n_{j}=\sqrt{\varepsilon_{j}^{\prime}-i \varepsilon_{j}^{\prime \prime}}
$$

is a medium refractive index.

Taking into account (1) and (2), the formula for the reflection coefficients of an EM wave for a three-layer system (Fig. 1) has the form:

$$
R=\frac{R_{12}+R_{23} e^{-2 i \beta}}{1+R_{12} R_{23} e^{-2 i \beta}} .
$$

Then the reflectivity of the medium in question is written as follows:

$$
|R|^{2}=\frac{R_{12}^{2}+R_{23}^{2}+2 R_{12} R_{23} \cos 2 \beta}{1+R_{12}^{2} R_{23}^{2}+2 R_{12} R_{23} \cos 2 \beta}
$$

where

$$
\beta=\frac{2 \pi}{\lambda} n 2 d \cos \theta
$$

In particular, for the normal incidence of the EM wave on this structure $\theta=0^{\circ}$, we obtain the following expressions:

$$
\begin{aligned}
& R_{12}=\frac{n_{1}-n_{2}}{n_{1}+n_{2}}, \\
& R_{23}=\frac{n_{2}-n_{3}}{n_{2}+n_{3}} .
\end{aligned}
$$

Applying the considered dependences to (1) - (7), it is possible to evaluate such an indicator of the quality of a substance as a CDC, which depends on the parameter $n-$ the refractive index of the medium.

We transform these dependences of the reflection coefficient in free space for Fig. 1 to the model for the case of a real waveguide measuring cell (WMC) (Fig. 2) - a threelayer medium of enclosed space from a segment of a metal rectangular waveguide, into which a plane EM wave is emitted. The EM wave propagates from the generator in the direction of the WMC with the main type of $H_{10}$. Then, we regard the above-considered problem for free space in the case when an EM wave falls from air medium 1 at an angle $\theta=0^{\circ}$ (Fig. 2) to the sample 2, while some part of the energy is reflected from the interface $1-2$, and some part passes through medium 2 and is reflected from the interface $2-3$ of the metal wall 3 and then multiple is reflected from both interfaces of the layers. For the case of a rectangular waveguide and a dielectric sample, we express the reflection coefficient through the longitudinal wave numbers. Then the expression for the complex coefficient of reflection of the wave from the first boundary of the media has the form: 


$$
R_{12}=\frac{h_{1}(f)-h_{2}\left(f, \bar{\varepsilon}_{2}\right)}{h_{1}(f)+h_{2}\left(f, \bar{\varepsilon}_{2}\right)}=\frac{\sqrt{k_{0}^{2}-\left(\frac{\pi}{a}\right)^{2}}-\sqrt{k_{0}^{2} \times \bar{\varepsilon}_{2}-\left(\frac{\pi}{a}\right)^{2}}}{\sqrt{k_{0}^{2}-\left(\frac{\pi}{a}\right)^{2}}+\sqrt{k_{0}^{2} \times \bar{\varepsilon}_{2}-\left(\frac{\pi}{a}\right)^{2}}}
$$

where $h_{1}$ is a longitudinal wave number or propagation constant of the EM wave for medium $1 ; h_{2}$ is a longitudinal wave number for medium $2 ; \bar{\varepsilon}_{2}$ is a complex relative permittivity of the medium $2 ; k_{0}=2 \pi / \lambda$ is a wave number for the medium $1 ; f$ is the operating frequency of the EM wave.

Considering that the bottom of the WMC 3 with the studied sample (Fig. 2) is metal, in expression (1) the reflection coefficient from this short circuit 3 can be written in the form $R_{23}=-1$ (provided that the losses are not taken into account in it) and it takes the form:

$$
R_{(f, \bar{\varepsilon})}=\frac{R_{12}-e^{-2 i \beta}}{1-R_{12} e^{-2 i \beta}} .
$$

Then, for the case of the presence of a sample inside the WMC (Fig. 2), we obtain a calculated mathematical model for the total complex reflection coefficient in the form:

$$
R(f, \bar{\varepsilon}, d)=\frac{R_{12}(f, \bar{\varepsilon})-\exp \left(-i 2 d \sqrt{k_{0}^{2} \times \bar{\varepsilon}-\left(\frac{\pi}{a}\right)^{2}}\right)}{1-R_{12}(f, \bar{\varepsilon}) \times \exp \left(-i 2 d \sqrt{k_{0}^{2} \times \bar{\varepsilon}-\left(\frac{\pi}{a}\right)^{2}}\right)}
$$

where $R_{12}$ is defined by expression (8).

\section{Numerical results}

To determine the desired value of the CDC of the substance included in expressions (8) - (10), we take into account the relationship between the reflection coefficient modulus $R$ and the standing wave voltage coefficient (VSWR) [9] in the form:

$$
\left|R_{i}\left(\varepsilon^{\prime}, \varepsilon^{\prime \prime}, f_{i}, d\right)\right|=\frac{K_{c i}^{u 3 M}-1}{K_{c i}^{u 3 M}+1},
$$

where $i=1,2,3 \ldots$ is the frequency number of the given range at which the VSWR is measured.

Using expressions (10) and (11), it is possible to determine the CDC of a substance. In this case, the VSWR measurements are performed at two closely spaced frequencies $f_{1}$ and $f_{2}$ for the VSWR values $i=1,2$ of the microwave range, in which the systematic error in the frequency reading of the measuring device is minimized and the real component of the CDC is constant. 
On this interval of two indications $i=1,2$, we determine the corresponding real and imaginary parts of the CDC of this substance.

Next, in a similar way, we determine the VSWR and then the CDC for the next pair of samples $i=2,3$ closely spaced frequencies and then over the frequency range.

Using expressions (10) and (11), the CDC values of several coal samples of the LC brand (lean concentrate), with different specific heat of combustion $\left(Q_{i}^{r}\right)$, used at electric and heat generating enterprises, were determined. The results are shown in Fig. 3, a, b.

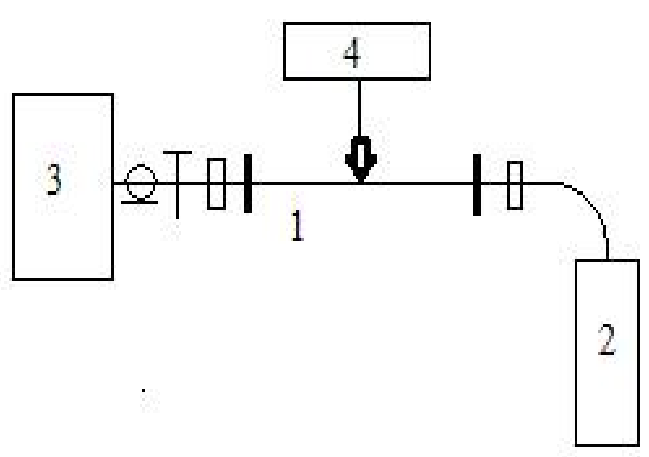

a

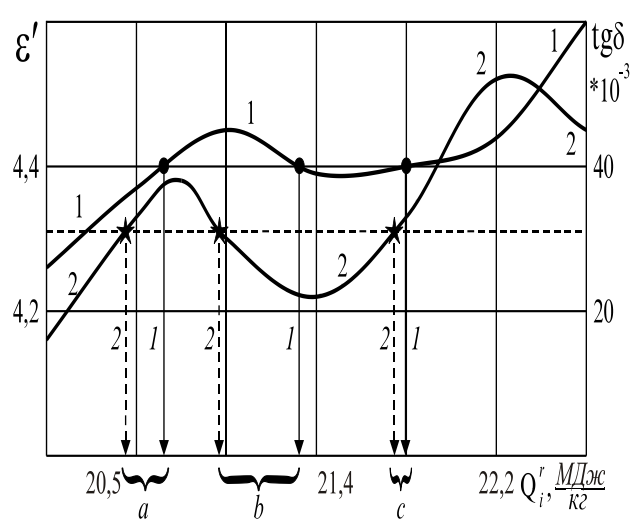

b

Fig. 3. Experimental installation (a): 1 - measuring waveguide line, 2 - WMC, 3 - microwave generator, 4 - measuring device;

CDC dependencies (b) of lean coal of the $L C$ brand on its $Q_{i}^{r}$ : curve $1-\varepsilon^{\prime}(Q)$, curve $2-\operatorname{tg} \delta(Q)$.

As measuring equipment for determining the VSWR, a measuring line (Fig. 3, a) can be used. However, for automation of measurements, it is advisable to use a modular automated measuring instrument of VSWR and attenuation of the type P2 (or P2M Russian Federation), a vector meter Spectrum Analyzer R\&S FSH (Germany), and other equipment interfaced with computers.

In another approach $[9,10]$ to measuring the dielectric characteristics of substances in waveguides were investigated of such exotic substances as foam structures in wide frequency ranges and waveguide sizes. In paper [9] dielectric properties in microwave band from 5.2 to $8.6 \mathrm{GHz}$ of the solid-state foam specimens were investigated in rectangular waveguides. In [10] a statistical analysis of measurements of solid-state foams in waveguides in the range of $2.0-8.6 \mathrm{GHz}$ was carried out, it was shown that their dielectric constant was in the range $1.26-1.52$ and its measurement accuracy had value in limits from 0.01 to $1.42 \%$, the dielectric loss tangent took values from 0.10 to 1.01 and its measurements accuracy was from 2 to $11 \%$.

\section{Conclusions}

The method for determining the CDC of substances and then the parameters of their quality considered in the paper was experimentally tested and the error in determining the dielectric constant of substances did not exceed $10 \%$.

The obtained experimental results on the investigation of the dielectric parameters of foams in the solid state allow us to recommend this research method of measuring the 
properties of various substances in both solid and liquid states for testing, applying, and spreading.

\section{Acknoledgement}

Authors express gratitude to the Associate Professor of Oles Honchar Dnipro National University S.V. Bukharov for his comments in the process of investigations on the topic of this work.

\section{References}

1. Brandt, A.A. Issledovaniye dielektrikov na SVCh. Moscow: Fizmatizd, 1964. 404 p. (in Russian).

2. Harvey, A.F. Tekhnika sverkhvysokikh chastot. T.1 / Per. s angl. pod red. V.I. Sushkevicha..-Moscow, 1965.- 783 p. (in Russian).

3. Born, M. Osnovy optiki / M. Born, E. Wolf / Per. s angl. pod red. G.P. Motulevicha - Moscow: Nauka, GRFML, 1973 (in Russian).

4. Brekhovskikh, L.M. Volny v sloistykh sredakh. Moscow: Nauka, 1973. - 343 p. (in Russian).

5. Viktorov, V.A. Radiovolnovyye izmereniya parametrov tehnologicheskikh protsessov / V.A. Viktorov, B.V. Lunkin, A.S. Sovlukov. - M.: Energoatomizdat, 1989. 208 p. (in Russian).

6. Ovsyanikov, V.V. Measurements of the complex permittivity by the waveguide and resonant cavity methods // Proceedings of the International. Conference on Actual Problems of Measuring Technique (Kyiv, Ukraine, 7-10 September, 1998. - P. 224 225.

7. Suk A.F. Sovremennyye metody nerazrushayushchego kontrolya v mashinostroyenii / A.F. Suk, V.P. Sebko, G.M. Suchkov, A.G. Lazarenko, V.V. Musil, A.M. Maystrenko. - Kharkov: NTU "KhPI", Uchebnyye posobiya, 2012. - 173 p. (in Russian).

8. Bukharov, S.V. Diahnostyka parametriv yakosti vuhillia i ridkykh naftoproduktiv elektromahnitnymy metodamy / S.V. Bukharov, Vl.V. Ovsianykov // Visnyk NTU «KPI». Seriya: Radiotekhnika, Radioaparatobuduvannia. - 2011. - Vyp. 45. - P. 120 129 (in Ukrainian).

9. Filinskyy, L. Computed dielectric properties of foam specimens measured in rectangular waveguides / L. Filinskyy // Conf. Proc.2014 Int.Conf on Mathematical Methods in Electromagnetic Theory. - Dnipropetrovsk, 2014. - CD. - P. 152 - 155.

10. Filins'kyy, L.A. Dielectric Properties of Foam Specimens Calculated on the Base of VSWR and Attenuation Characteristics / L.A. Filins'kyy // Proceedings of $19^{\text {th }}$ International Seminar- Workshop on Direct and Inverse Problems of Electromagnetic and Acoustic Wave Theory (DIPED’14). - Tbilisi, Georgia, September 22-25, 2014. - P. 48 51 . 